\title{
A Quad Band Circular Patch Antenna with Fractal Elements for S-Band and C-Band Applications
}

\author{
Amandeep Kaur \\ M.Tech Scholar \\ Electronics and Communication \\ Engineering Deptt. \\ Amritsar College of \\ Engineering and Technology, \\ Amritsar
}

\author{
Narinder Sharma \\ Associate Professor \\ Electronics and Communication \\ Engineering Deptt. \\ Amritsar College of \\ Engineering and Technology, \\ Amritsar
}

\begin{abstract}
In this paper a quad band circular patch antenna with fractal elements is proposed for S-band and C-band applications. The designed antenna operates at four different frequency bands such as $2.86 \mathrm{GHz}, 4.76 \mathrm{GHz}, 6.50 \mathrm{GHz}$ and $7.42 \mathrm{GHz}$ with bandwidth of $110 \mathrm{MHz}, 110 \mathrm{MHz}, 110 \mathrm{MHz}$ and $90 \mathrm{GHz}$ respectively of wireless applications with a return loss, VSWR and gain at acceptable level. The proposed antenna is fed by using inset line feeding technique. Antenna is designed by using low cost FR4 glass epoxy substrate having dimensions $35 \times 44.92 \times 1.6 \mathrm{~mm}^{3}$ with a relative permittivity of 4.4. Proposed antenna is designed and simulated using High Frequency Structure Simulator (HFSS) Version 13 software and different antenna parameters are simulated and discussed in this manuscript
\end{abstract}

\section{Keywords}

Fractal elements, gain, FR4, VSWR

\section{INTRODUCTION}

Fractal antennas experienced large growth in recent years in the field of wireless communication and become the main subject of many researches [1]. Benoit Mandelbrot in 1975 introduces the fractal geometries to achieve the multiband and wideband characteristics [2]. These characteristics are originated by the fractal geometrical properties such as selfsimilarity and space-filling [3]. Fractal geometries repeat their geometries by a scale at particular dimensions in successive iterations [4] the geometry for the patch of fractal antenna is the similar pattern of the whole geometry at different scales to make different iterations and to obtain the better results. Selfsimilarity property of antenna is used to obtain the multiband behavior and the space-filling property is used to achieve miniaturization of antenna [5]. Fractal antenna also has many features like small size, less weight and better performance over different wireless applications [6] in the frequency bands such as L-band (1-2GHz), S-band (2-4GHz), C-band (4$8 \mathrm{GHz}), \mathrm{X}$-band $(8-12 \mathrm{GHz}), \mathrm{Ku}-$ band $(12-18 \mathrm{GHz})$ etc [7]. In this paper two different iterations of proposed antenna has been designed and different parameters are analyzed for both the iterations. The detailed designs, graphical and theoretical values of results are discussed in the further sections of this manuscript.

\section{ANTENNA DESIGN}

The essential parameters are taken into consideration while designing the patch antennas such as resonant frequency, dielectric constant, thickness of substrate and the shape of the radiator/patch.
In this work a circular patch is designed by using equation (1) and (2). The FR4 glass epoxy substrate with dielectric constant 4.4 and thickness of $1.6 \mathrm{~mm}$. The resonant frequency used for this design is $3.2 \mathrm{GHz}$. By using all these parameters the radius of circular patch is calculated and found to be $12.6 \mathrm{~mm}$ and the circle of radius $2.52 \mathrm{~mm}$ is extracted from the centre of patch. The 1st iteration of proposed antenna is shown in Figure 1 and the parametric values are shown in Table 1.

$a=F\left\{1+\frac{2 h}{\pi F \varepsilon_{r}}\left[\ln \left(\frac{\pi F}{2 \mathrm{~h}}\right)+1.7726\right]\right\}^{\frac{-1}{2}}$

(1)

$F=\frac{8.791 \times 10^{9}}{f_{r} \sqrt{\varepsilon_{r}}}$

Where,

$h=$ Substrate height.

$\mathcal{E}_{r}=$ Relative permittivity of the substrate.

$a=$ Radius of circular patch.

$f_{r=}$ Resonant frequency.

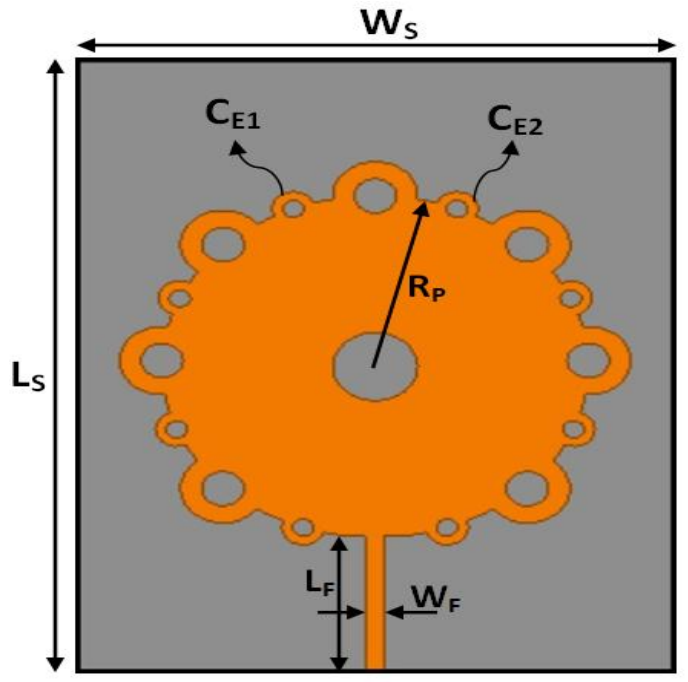

Figure 1: $1^{\text {st }}$ iteration of proposed fractal antenna 
Table 1: Parametric values of $1^{\text {st }}$ iteration of proposed antenna

\begin{tabular}{|c|c|c|c|}
\hline S. No. & Parameters & Description & Values \\
\hline 1. & $\mathrm{~W}_{\mathrm{S}}$ & Width of Substrate & $35 \mathrm{~mm}$ \\
\hline 2. & $\mathrm{~L}_{\mathrm{S}}$ & Length of Substrate & $44.9 \mathrm{~mm}$ \\
\hline 3. & $\mathrm{R}_{\mathrm{P}}$ & Radius of Patch & $12.6 \mathrm{~mm}$ \\
\hline 4. & $\mathrm{~W}_{\mathrm{F}}$ & Width of Feed Line & $1 \mathrm{~mm}$ \\
\hline 5. & $\mathrm{~L}_{\mathrm{F}}$ & Length of Feed Line & $10 \mathrm{~mm}$ \\
\hline
\end{tabular}

The circular fractal elements CE1 and CE2 as shown in Figure 1 is designed by taking the radius $\mathrm{R} 1=2.52 \mathrm{~mm}$ which is $1 / 5$ th of the radius of circular patch, radius $\mathrm{R} 2=1.26 \mathrm{~mm}$ which is the 1/10th of the radius of circular patch and R3 $=0.63 \mathrm{~mm}$ which is the $1 / 20$ th of the radius of circular patch. The procedure for designing the circular fractal elements CE1 and CE2 is shown in Figure 2.
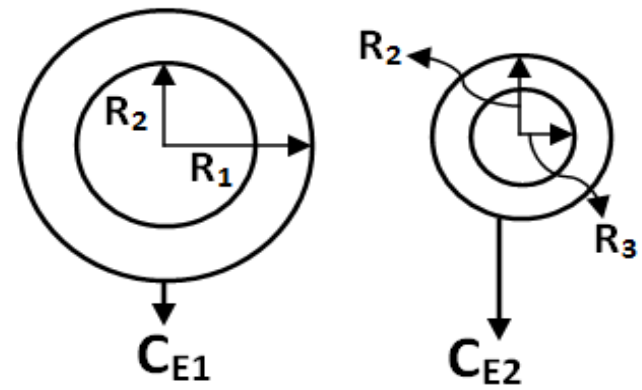

Figure 2: Procedure for designing fractal elements

The 2nd iteration of proposed antenna is designed by taking all the dimensions of 1 st iteration as same. But the inset cuts are introduced along with the line feed to increase the number of frequency bands and the gain of proposed antenna. The length LI and width WI of inset cut is $4 \mathrm{~mm}$ and $1 \mathrm{~mm}$ respectively. The 2 nd iteration of proposed antenna is shown in Figure 3.

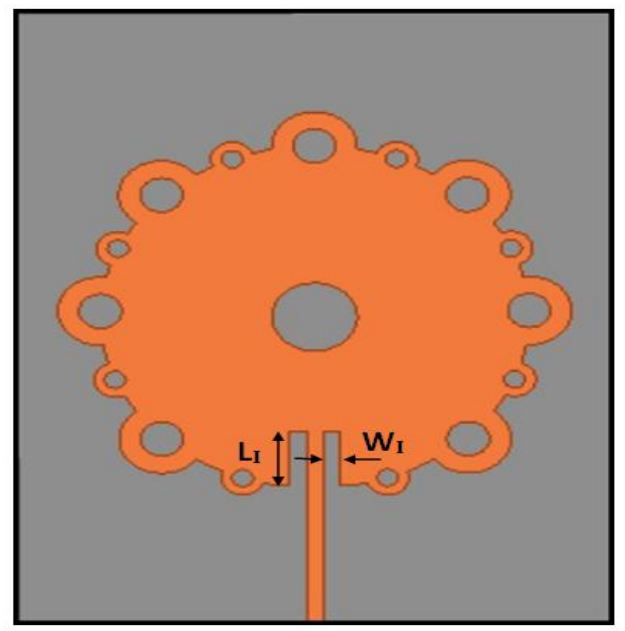

Figure 3: $1^{\text {st }}$ iteration of proposed fractal antenna

\section{RESULT AND DISCUSSIONS}

\subsection{Return loss and Bandwidth}

The return loss v/s frequency curve for 1 st and 2 nd iterations of proposed antenna is shown in Figure 4 and 5 respectively. 1 st iteration of proposed antenna resonates at three frequency bands such as $2.86 \mathrm{GHz}, 4.72 \mathrm{GHz}$ and $7.42 \mathrm{GHz}$ with a bandwidth of $120 \mathrm{MHz}, 100 \mathrm{MHz}$ and $180 \mathrm{MHz}$ respectively. The 2nd iteration of proposed antenna resonates at four frequency bands such as $2.86 \mathrm{GHz}, 4.76 \mathrm{GHz}, 6.50 \mathrm{GHz}$ and $7.42 \mathrm{GHz}$ with corresponding bandwidth of $110 \mathrm{MHz}$, $110 \mathrm{MHz}, 110 \mathrm{MHz}$ and $90 \mathrm{MHz}$ respectively. The value of return loss for 1st and 2nd iteration of proposed antenna at all the frequency bands is shown in Table 2 .

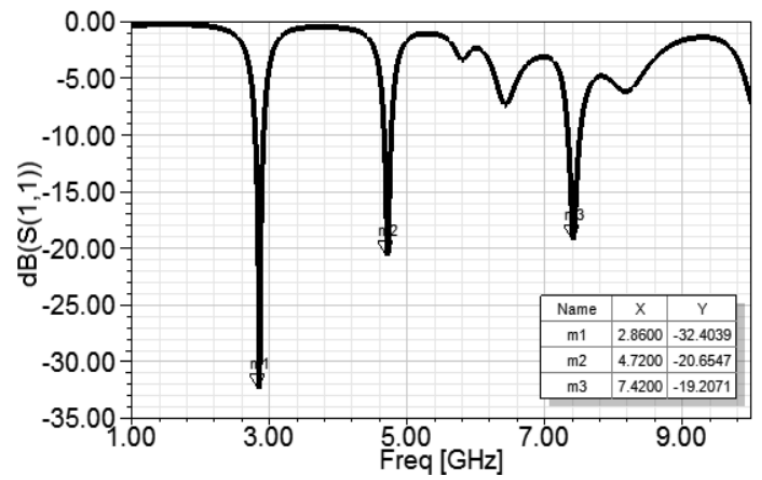

Figure 4: Return loss v/s frequency Curve for $1^{\text {st }}$ iteration of proposed antenna

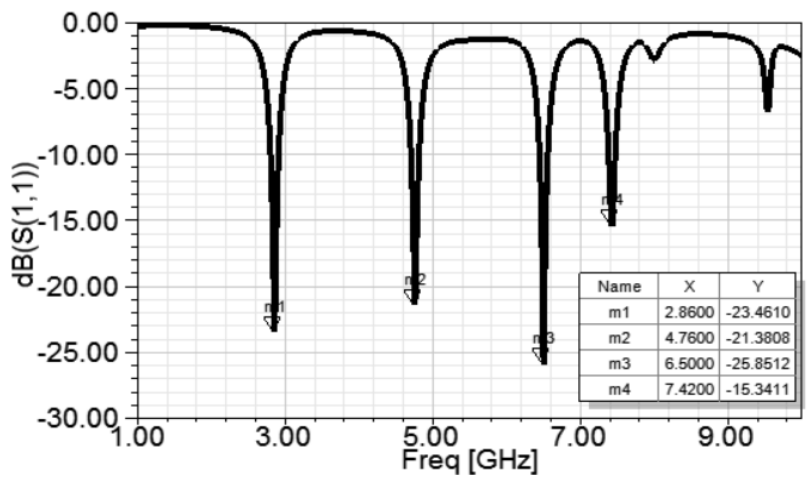

Figure 5: Return loss v/s frequency curve for $2^{\text {nd }}$ iteration of proposed antenna

\subsection{VSWR}

The VSWR v/s frequency curve of 1st and 2nd iteration of proposed antenna is shown in Figure 6 and 7 respectively. The value of VSWR for all the frequency bands is below 2 which is the acceptable level of VSWR for the antenna to work efficiently.

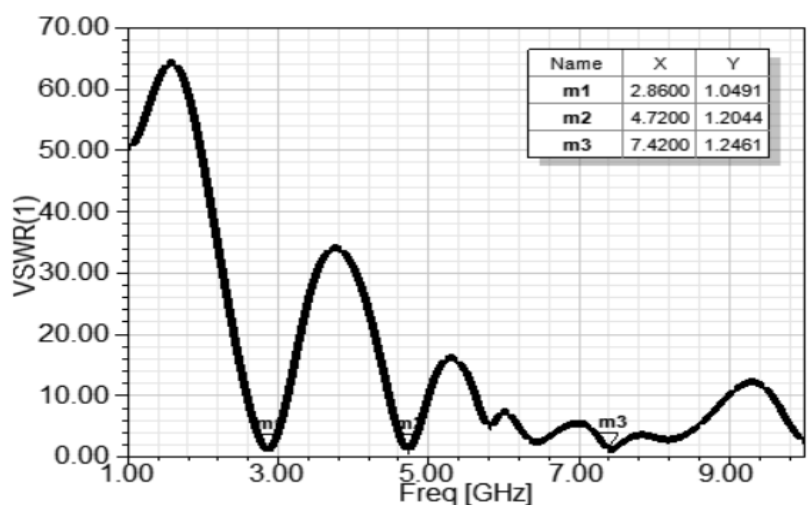

Figure 6: VSWR v/s frequency curve for $1^{\text {st }}$ iteration of proposed antenna 


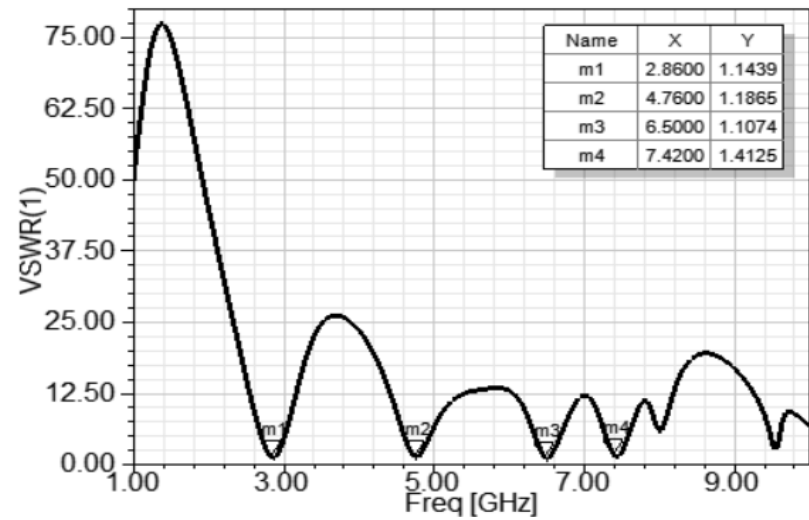

Figure 7: VSWR v/s frequency curve for $2^{\text {nd }}$ iteration of proposed antenna

\subsection{Gain}

The gain of multiband antenna should be positive and at acceptable level for all the resonant frequency bands. The acceptable value of gain is greater than $3 \mathrm{~dB}$ for the antenna to work efficiently at respective frequency band. The gain of proposed antenna for 1st iteration is not at acceptable level and to increase the gain the 2 nd iteration of proposed antenna is designed by using inset line feeding technique. The 3D gain plot for all the frequency bands of 2nd iteration in shown in Figure 8, 9, 10 and 11 respectively and the values are shown in Table 2.

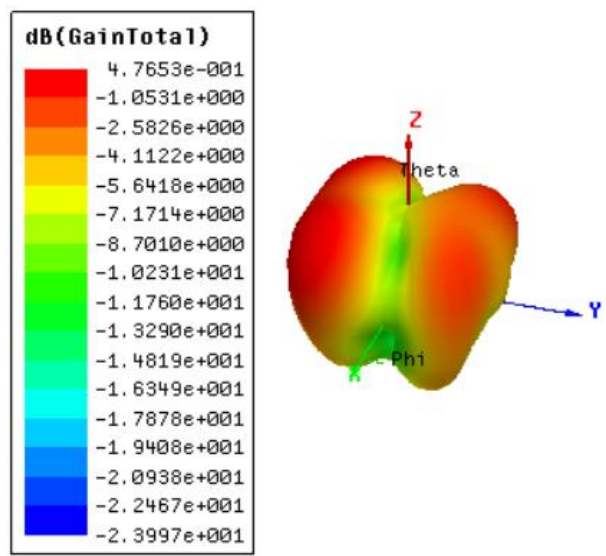

Figure 8: 3D gain plot for $2^{\text {nd }}$ iteration at $2.86 \mathrm{GHz}$ frequency

\begin{tabular}{|c|}
\hline dB (Gain Tota 1) \\
$3.8363 e+000$ \\
$1.9120 e+000$ \\
$-1.2287 e-002$ \\
$-1.9366 e+000$ \\
$-3.8609 e+000$ \\
$-5.7852 e+000$ \\
$-7.7995 e+000$ \\
$-9.6338 e+000$ \\
$-1.1558 e+001$ \\
$-1.3482 e+001$ \\
$-1.5407 e+001$ \\
$-1.7331 e+001$ \\
$-1.9255 e+001$ \\
$-2.1180 e+001$ \\
$-2.3104 e+001$ \\
$-2.5028 e+001$ \\
$-2.6953 e+001$ \\
\hline
\end{tabular}

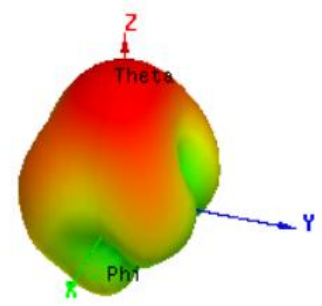

Figure 9: 3D gain plot for $2^{\text {nd }}$ iteration at $4.76 \mathrm{GHz}$ frequency
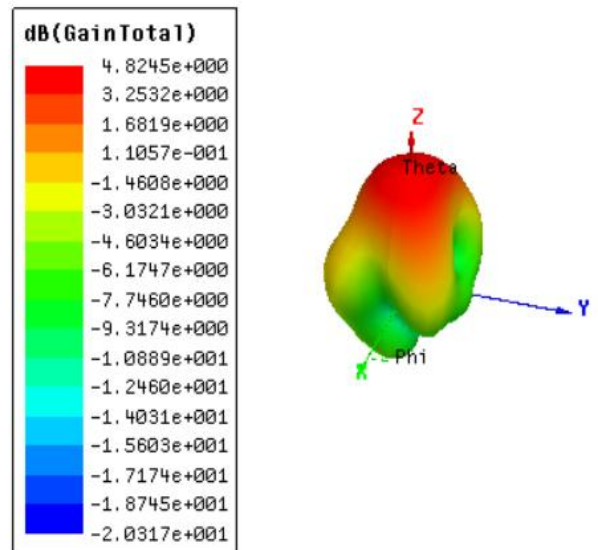

Figure 10: 3D gain plot for $2^{\text {nd }}$ iteration at $6.50 \mathrm{GHz}$ frequency
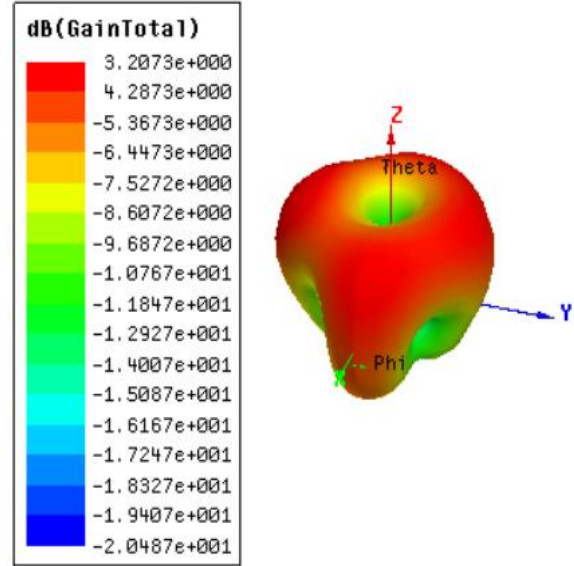

Figure 11: 3D gain plot for $2^{\text {nd }}$ iteration at $7.42 \mathrm{GHz}$ frequency

\subsection{Radiation Pattern}

Radiation pattern shows the directional capabilities and antenna efficiency in a particular direction. It is the graphical representation of the antenna efficiency in the azimuth and elevation plane. The radiation pattern at phi $=0$ degree and phi $=90$ degree for the frequency bands of 2 nd iteration is shown in Figure 12, 13, 14 and 15 respectively.

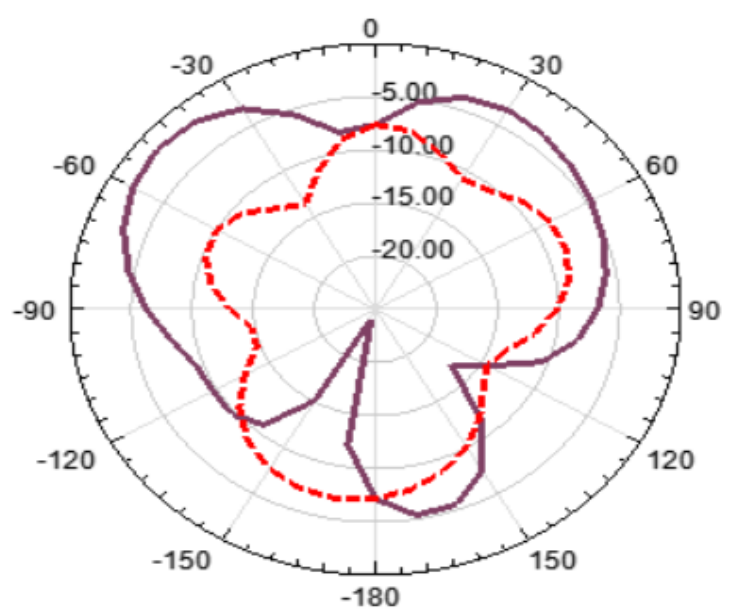

Figure 11: 2D radiation pattern for $2^{\text {nd }}$ iteration at $2.86 \mathrm{GHz}$ frequency 


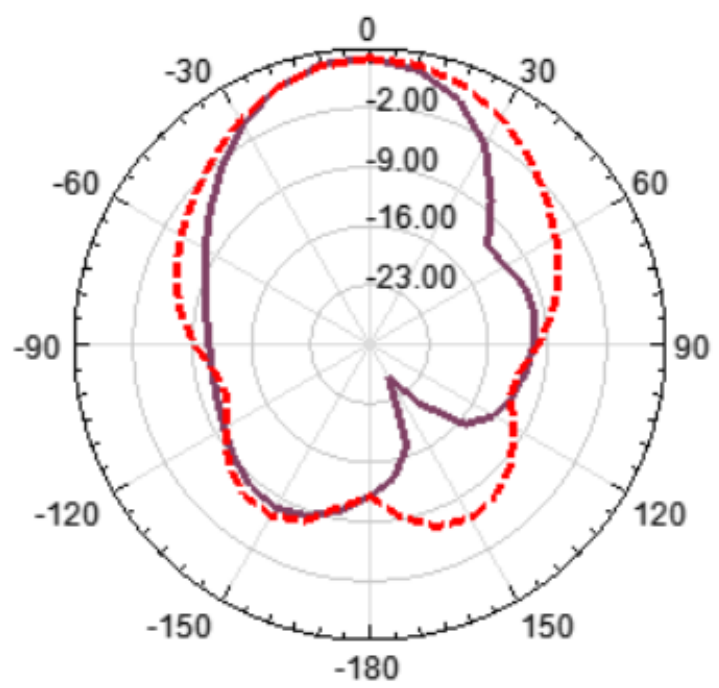

Figure 12: 2D radiation pattern for $2^{\text {nd }}$ iteration at 4.76GHz frequency

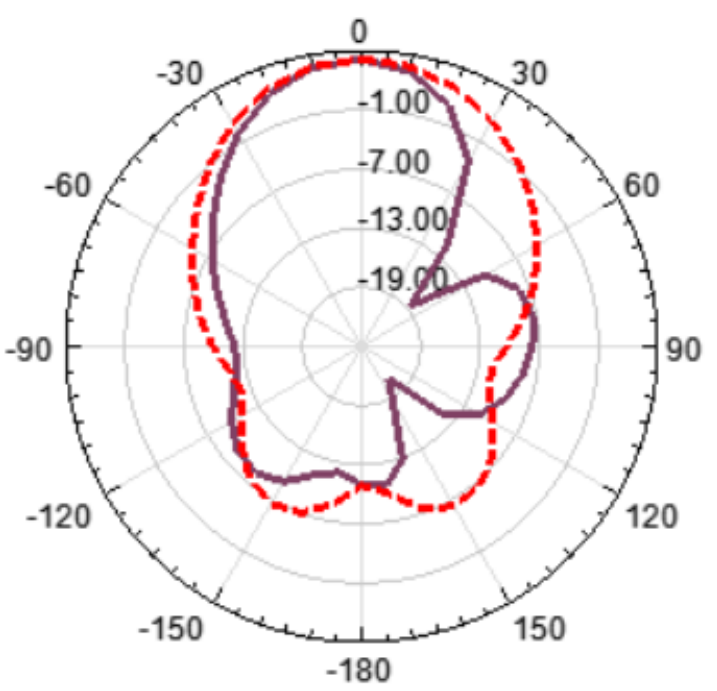

Figure 13: $2 D$ radiation pattern for $2^{\text {nd }}$ iteration at $6.50 \mathrm{GHz}$ frequency

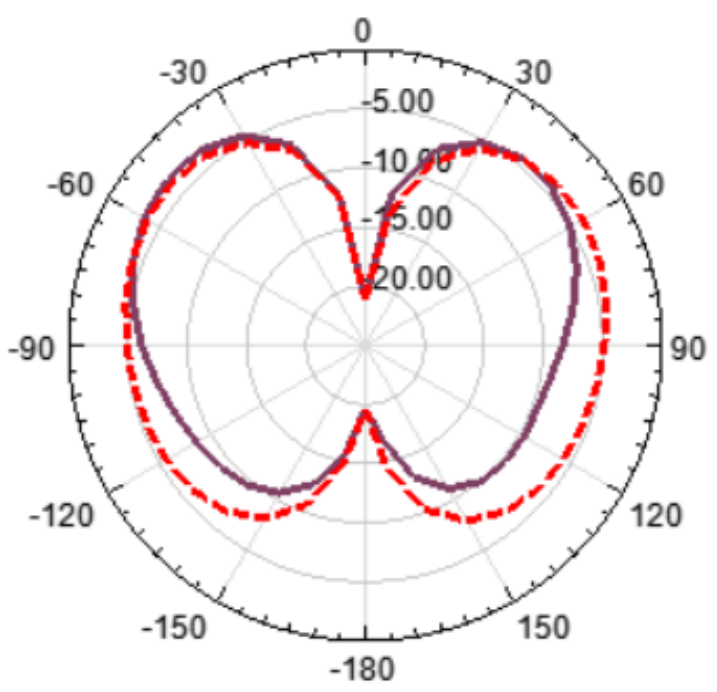

Figure 13: 2D radiation pattern for $2^{\text {nd }}$ iteration at 7.42GHz frequency
Table 1. Simulated results of $1^{\text {st }}$ and $2^{\text {nd }}$ iteration of proposed antenna

\begin{tabular}{|c|c|c|c|c|}
\hline $\begin{array}{c}\text { Iteration } \\
\text { No. }\end{array}$ & $\begin{array}{c}\text { Resonant } \\
\text { frequencies } \\
\text { in GHz }\end{array}$ & $\begin{array}{c}\text { Return } \\
\text { Loss in } \\
\mathbf{d B}\end{array}$ & $\begin{array}{c}\text { Gain in } \\
\mathbf{d B}\end{array}$ & VSWR \\
\hline \multirow{4}{*}{$\begin{array}{c}1^{\text {st }} \\
\text { iteration }\end{array}$} & 2.86 & -32.40 & 1.96 & 1.04 \\
\cline { 2 - 5 } & 4.72 & -20.65 & -3.26 & 1.20 \\
\cline { 2 - 5 } & 7.42 & -19.20 & -3.19 & 1.24 \\
\hline \multirow{4}{*}{$2^{\text {nd }}$} & 2.86 & -23.46 & 4.76 & 1.14 \\
\cline { 2 - 5 } iteration & 4.76 & -21.38 & 3.83 & 1.18 \\
\cline { 2 - 5 } & 6.50 & -25.85 & 4.82 & 1.10 \\
\cline { 2 - 5 } & 7.42 & -15.34 & 3.20 & 1.47 \\
\hline
\end{tabular}

\section{CONCLUSIONS}

This paper presents the design of a quad band circular patch antenna using fractal elements for S-band and C-band applications. The inset line feed is used in the 2nd iteration of proposed antenna to enhance the performance parameters further. By employing inset cuts the gain of antenna shows the values at acceptable level for all the frequency bands. Maximum gain of $4.82 \mathrm{~dB}$ is obtained at the frequency of $6.50 \mathrm{GHz}$. The 2 nd iteration of proposed antenna works on four resonant frequencies whereas the 1st iteration works only at three frequencies. The main aim of this work is to enhance the gain and resonant frequency band of proposed antenna. Proposed antenna can be used for different applications in the frequency bands such as S-band and C-band.

\section{REFERENCES}

[1] P. Z. Petkov, M. R. Kolev and B. G. Bonev, "Fractal yagi antenna," IEEE, Conference on microwave techniques (COMITE), pp. 1-3, 2015.

[2] K. Kharat, S. Dhoot and J. Vajpai, "Design of compact multiband fractal antenna for WLAN and WiMAX applications," IEEE, Internationsl Conference on Pervasive Computing (ICPC), 2015.

[3] T. Landen, O. Losito, G. Palma, V. Portosi, A. Jouanneaux and F. Prudenzano, "Multiple rhombus monopole antenna," GeMic, Germany, pp. 367-370, 2015.

[4] H. Orazi and H. Soleimani, "Miniaturisation of the triangular patch antenna by the novel dual reverse arrow fractal, "IET Microwave, Antenna and Propagation, pp. $1-7,2014$

[5] S. Subramaniam, S. Dhar, L. Osman, K. Zeouga and A. Gharsallah, "Miniaturization of wearable electro-textile antennas using Minkowski fractal geometry," IEEE, 9781-4799-3540-6, pp. 309-310, 2014.

[6] S. Yadav, P. Jain and A. Dadhich, "A novel approach to bandwidth enhancement of multi-fractal antenna," IEEE, International Conference on Signal Propagation and Computer Technology (ICSPCT), pp. 205-208, 2014.

[7] M. Nandal, Sagar and R. Goel, "Optimal and new design of T-shaped tri band fractal microstrip patch antenna for wireless networks," IEEE, 6 ${ }^{\text {th }}$ (ICCICN), pp. 92-96, 2014. 